Personalidade Acadêmica Homenageada:

Carlos Aurélio Mota de Souza (Universidade Ibirapuera - UNIB)

\title{
A CORRUPÇÃO NA ADMINISTRAÇÃO PÚBLICA BRASILEIRA: OS ATOS CORRUPTOS E A EFICÁCIA DOS INSTRUMENTOS JURÍDICOS INIBIDORES DE SUA PRÁTICA NO ORDENAMENTO BRASILEIRO
}

\section{BRUNO ROBERTO VOSGERAU}

Mestrando do Programa Direito Empresarial e Cidadania (Centro Universitário Curitiba - UniCuritiba) (2017). Especializado em direito do trabalho e processual do trabalho pela Pontifícia Universidade Católica do Paraná (2015). Especializado em direito público pelo Centro universitário Maringá (UniCesumar) (2015). Graduado em Direito pela Universidade Católica de Brasília (2011). Experiência com contencioso de massa, contratos e relação de consumo. Experiência em direito tributário e administrativo.

\section{OBJETIVOS}

Em virtude dos enormes escândalos de corrupção que têm tomado a mídia nos dias atuais, a análise para as formas como esta mazela social se desenvolve e possíveis soluções para que seja evitada, ou reduzida, demonstra relevância apta a justificar a presente pesquisa.

Os objetivos deste trabalho delimitam-se a buscar o conceito do termo "corrupção", de modo que seja possível indicar quais os atos praticados no âmbito da Administração Pública brasileira são considerados corruptos, e em que medida os instrumentos jurídicos contidos no ordenamento jurídico brasileiro são eficazes para evitar o seu desenvolvimento ou prática. 
Personalidade Acadêmica Homenageada:

Carlos Aurélio Mota de Souza (Universidade Ibirapuera - UNIB)

A presente pesquisa possui como marco inicial a análise do conceito do termo "corrupção", de modo a permitir a identificação de quais são os atos pelos quais a corrupção na Administração Pública brasileira se desenvolve, verificando se os instrumentos jurídicos inibidores previstos no ordenamento brasileiro são eficazes para combater a sua prática.

Para que seja possível obter os resultados pretendidos, a pesquisa se utiliza da revisão bibliográfica de autores nacionais e estrangeiros que abordam o tema corrupção e da análise de dados de pesquisas realizadas por organismos internacionais sobre o tema.

O método da pesquisa a ser aplicado será o dedutivo, partindo da premissa maior correspondente ao conceito do termo "corrupção", que permitirá a identificação de quais os atos praticados na/pela Administração Pública brasileira são considerados corruptos, de modo que analisando os instrumentos jurídicos inibidores constantes no ordenamento jurídico são eficazes no seu combate.

\section{RESUMO}

Preliminarmente, é preciso ter a noção do que deve ser considerado como corrupção, pois o termo é extremamente abrangente e contempla diversas conotações e interpretações, muito em virtude disso é mais fácil apresentar uma lista meramente ilustrativa dos atos que podem ser considerados corruptos do que propriamente criar uma única definição, porém para a Transparência Internacional (TI) a corrupção é caracterizada com o abuso de um poder confiado a algum indivíduo (tarefas, funções que se espera que sejam cumpridas) com o propósito de que obtenha ganhos pessoais por intermédio do desrespeito à lei e da subversão das metas traçadas em virtude da posição que ocupa seja no governo, seja em instituição privada ${ }^{1}$.

1 ROSE-ACKERMAN, Susan. PALIFKA, Bonnie J. Corruption and government: causes, consequences, and reform, second edition. New York, NY: Cambridge University Press, 2016. p. 78. 


\section{Personalidade Acadêmica Homenageada:}

Carlos Aurélio Mota de Souza (Universidade Ibirapuera - UNIB)

A corrupção é o meio ilegítimo pelo qual se exerce influência, no caso do Estado, é a forma ilícita de se influenciar nas decisões públicas, de modo que as suas manifestações podem ocorrer em qualquer um dos Poderes (Executivo, Legislativo, Judiciário) e intervirá em três níveis: a) na fase de elaboração das decisões, b) na fase de aplicação das normas legais e c) na fase de execução das decisões adotadas².

A interposição de um interesse privado sobre o interesse público na Administração Pública caracteriza 0 ato de corrupção, apenas como título exemplificativo, cita-se como por exemplo o nepotismo, o suborno, a extorsão, a troca de favores, o apadrinhamento, a fraude judicial, a fraude no serviço público, os desvios de verbas, o tráfico de influência e os conflitos de interesses ${ }^{3}$.

Identificados os atos de corrupção passíveis de serem praticados no âmbito da Administração Pública, faz-se necessário verificar no ordenamento brasileiro quais são os instrumentos jurídicos para inibi-los.

A análise pelo direito sancionador se inicia pelo Código Penal, no título IX entre os artigos 312 e 336 há a previsão de crimes contra a Administração Pública brasileira, praticados por funcionários públicos e por particulares.

Também há leis esparsas sobre o tema, em especial a Lei o 8.666/93 que regulamenta os contratos e licitações, a Lei $n=8429 / 92$ que trata sobre os atos de improbidade administrativa e a Lei no 12.846 /13 que sanciona administrativamente e civilmente atos de corrupção contra a Administração Pública nacional ou estrangeira.

Porém, leis como a Lei de Acesso à Informação (Lei no 12.527/11) também é um exemplo de instrumento jurídico para combater os crimes de corrupção na Administração Pública, isso porque obriga, fora os casos excepcionais, que haja a publicidade dos atos praticados ou que serão praticados, permitindo assim maior controle da própria sociedade, e caso verificada qualquer irregularidade poderá

2 MILESKI, Helio Saul. O Estado contemporâneo e a corrupção, 1 ed. Belo Horizonte: Fórum, 2015. p. 362-362.

3 ROSE-ACKERMAN, Susan. PALIFKA, Bonnie J. Corruption and government: causes, consequences, and reform, second edition. New York, NY: Cambridge University Press, 2016. p. 89. 
Personalidade Acadêmica Homenageada:

Carlos Aurélio Mota de Souza (Universidade Ibirapuera - UNIB)

denunciar às autoridades competentes como o Ministério Público para que providências sancionadora sejam tomadas.

Por fim, a pesquisa buscará verificar se os instrumentos jurídicos para combater os atos de corrupção no âmbito da Administração Pública são eficazes, de modo a concluir se efetivamente podem ser considerados inibidores de sua prática.

\section{RESULTADOS OBTIDOS OU ESPERADOS}

Ao final da pesquisa, com os subsídios obtidos, identificados quais atos podem ser considerados corruptos no âmbito da Administração Pública, bem como os instrumentos jurídicos no ordenamento brasileiro inibidores de sua prática, pretende-se concluir sobre a sua eficácia, se possuem a aptidão de evitar a prática dos atos identificados como ímprobos.

PALAVRAS CHAVE: Corrupção; Administração; Pública; Instrumentos; Jurídicos.

\section{REFERÊNCIAS}

GOMES, Luis Flávio. O jogo sujo da corrupção. Bauru: Astral Cultural, 2017.

MILESKI, Helio Saul. O Estado contemporâneo e a corrupção, 1 ed. Belo Horizonte: Fórum, 2015.

ROSE-ACKERMAN, Susan. PALIFKA, Bonnie J. Corruption and government: causes, consequences, and reform, second edition. New York, NY: Cambridge University Press, 2016.

SOUZA, Jorge Munhoz de. QUEIROZ, Ronaldo Pinheiro. Lei anticorrupção e temas de compliance, 2 ed, Salvador: Editora JusPodivm, 2016.

PEDROSO, Fernando Gentil Gizzi de Almeida. HERNANDES, Luiz Eduardo Camargo Outeiro. Direito penal econômico. Salvador: Editora JusPodivm, 2017. 